\title{
ORGANOGÊNESE IN VITRO A PARTIR DE EXPLANTE CAULINAR NA REGENERAÇÃO DE CLONES DE Eucalyptus grandis W. Hill ex Maiden X $E$. urophylla S. T. Blake ${ }^{1}$
}

\author{
Elisa Cristina Soares de Carvalho Alves ${ }^{2}$, Aloisio Xavier ${ }^{3}$, Wagner Campos Otoni ${ }^{4}$
}

\begin{abstract}
RESUMO - Com o objetivo de testar a regeneração in vitro por organogênese a partir de explante caulinar de três clones híbridos de Eucalyptus grandis x Eucalyptus urophylla, foram avaliados os efeitos dos reguladores de crescimento TDZ [1-fenil-3-(1,2,3-tiadiazol-5-il)uréia], BAP(6-benzilaminopurina) eANA (ácido naftalenoacético). De modo geral, pôde-se observar resposta diferenciada dos clones quanto a intensidade, textura, coloração e grau de oxidação dos calos, em função dos tratamentos com os reguladores de crescimento. Os melhores resultados de calejamento foram dos tratamentos com a combinação dos reguladores de crescimento TDZ $\left(0,5 \mathrm{mg} \mathrm{L}^{-1}\right)$ e ANA $\left(0,1 \mathrm{mg} \mathrm{L}^{-1}\right)$, obtendo-se $100 \%$ de calejamento no explante caulinar. Houve a formação de estruturas nodulares compactas, principalmente na extremidade dos explantes caulinares, sendo essas regiões responsáveis pela regeneração de gemas adventícias. Em relação à regeneração, a melhor resposta foi obtida com $1,0 \mathrm{mg} \mathrm{L}^{-1}$ BAP.
\end{abstract}

Palavras-chave: Micropropagação, reguladores de crescimento e propagação in vitro.

\section{IN VITRO REGENERATION FROM STEM EXPLANTS OF Eucalyptus grandis $X$ E. urophylla CLONES THROUGH ORGANOGENESIS}

\begin{abstract}
With the objective of testing in vitro regeneration through organogenesis from stem explants of three hybrid clones of Eucalyptus grandis $x$ Eucalyptus urophylla, the effects of the growth regulators TDZ [1-phenil-3-(1, 2, 3-thiadiazol-5-il)urea], BAP (6-benzilaminopurine) and NAA (Naphthalene acetic acid) were evaluated. In general, a differentiated clone response in relation to intensity, texture, color and oxidation degree of calli was observed due to growth regulator treatments. The best results in callus formation were recorded for the treatments with the combination $\operatorname{TDZ}\left(0,5 \mathrm{mg} \mathrm{L}^{-1}\right)$ and ANA $\left(0,1 \mathrm{mg} \mathrm{L}^{-1}\right)$, achieving $100 \%$ of callus formation from the stem explants. Compact node structures appeared mainly in the extremities of the stem explants, being those areas responsible for the regeneration of adventitious buds. The best regeneration response was obtained with $1,0 \mathrm{mg} \mathrm{L}^{-1} \mathrm{BAP}$.
\end{abstract}

Keywords: microprogation, growth regulator.and in vitro propagation.

\section{INTRODUÇÃO}

O gênero Eucalyptus inclui a maioria das espécies florestais utilizadas no estabelecimento de plantações em áreas tropicais e subtropicais do mundo, sendo a clonagem de indivíduos superiores uma alternativa de fundamental importância e aplicação no setor flo- restal. Nesse contexto, atualmente a micropropagação de eucalipto tem sido utilizada no rejuvenescimento de clones, visando à formação e manutenção de microjardim clonal, os quais constituem a base para a produção de mudas pelo método da microestaquia (XAVIER e COMÉRIO, 1996).

\footnotetext{
${ }^{1}$ Recebido para publicação em 30.4.2003 e aceito para publicação em 10.8.2004.

${ }^{2}$ Programa de Pós-Graduação em Ciência Florestal. E.mail: <soarescarvalho@ @otmail.com>.

${ }^{3}$ Departamento de Engenharia Florestal - Universidade Federal de Viçosa, 36.570-000, Viçosa-MG. E.mail: <xavier@ ufv.br>.

${ }^{4}$ Departamento de Biologia Vegetal, Universidade Federal de Viçosa, 36.570-000, Viçosa-MG. E.mail: <wotoni@ ufv.br>.
} 
Aliada à micropropagação, nos últimos anos a transformação genética em plantas lenhosas tem despertado atenção no setor florestal, sendo uma realidade em algumas situações. Trabalhos com eucalipto têm sido desenvolvidos nessa linha (CHEN et al.,1996; SERRANO et al., 1996; MULLINS et al., 1997; HO et al., 1998), contudo o sucesso de programas de transformação estável de genes depende da capacidade de regeneração da espécie em estudo (FERREIRA et al., 1998).

Segundo Mullins et al. (1997), os procedimentos convencionais de micropropagação em eucalipto se dão pela ativação de gemas axilares em cultura. Entretanto, a propagação in vitro por organogênese de explantes foliares também possui a capacidade de regenerar grande número de plantas, e com potencial para ser automatizada.

Protocolos eficientes de micropropagação de eucalipto pela via organogênica foram apresentados por Subbaiah e Minocha (1990), Tibok et al. (1995), Chen et al. (1996), Azmi et al. (1997), Mullins et al. (1997), Ho et al. (1998) e Bandyopadhyay et al. (1999), os quais utilizaram material juvenil como fonte de explantes, a exemplo de cotilédones e hipocótilos. Trabalhos de organogênese in vitro utilizando explantes foliares de clones micropropagados de eucalipto grandis foram realizados por Lainé e David (1994), os quais constataram a existência de diferenças no requerimento com relação aos reguladores de crescimento, para organogênese, entre os diferentes clones, e que o tamanho do explante não afeta a habilidade destes de produzir gemas. Esses autores verificaram, também, que as condições de luminosidade constituem importante parâmetro, sendo os melhores resultados obtidos na ausência de luz nas primeiras quatro semanas de cultivo.

Normalmente, na propagação in vitro os reguladores de crescimento constituem-se numa primeira etapa a ser abordada, em que o modo de interação entre auxinas e citocininas é freqüentemente dependente da espécie da planta e do tipo de tecido utilizado na cultura (COENEN e LOMAX,1997; PIERIK, 1997). A maneira complexa com que os reguladores de crescimento e as células se interagem indica que, se o tecido não está em um estádio responsivo, ele não irá responder adequadamente aos reguladores de crescimento exógenos, não importando em quais concentrações e combinações esses reguladores são utilizados. A ausência na resposta a um regulador de crescimento é freqüentemente um problema maior quando explantes de plantas adultas são utilizados, em comparação com material juvenil (BONGAe VONADERKAS, 1992).

Dessa forma, métodos eficientes para regeneração de clones selecionados pela via organogênica, utilizando como explante folha de material rejuvenescido, poderiam constituir-se numa alternativa de multiplicação vegetativa, além de atender a programas de transformação genética. Assim, o objetivo do presente estudo foi avaliar os efeitos dos reguladores de crescimento TDZ, BAP e ANA no desempenho organogênico in vitro de explante caulinar na regeneração de três clones de Eucalyptus grandis x Eucalyptus urophylla.

\section{MATERIAL E MÉTODOS}

\subsection{Material experimental}

Foram utilizados três clones híbridos de Eucalyptus grandis provenientes das empresas V\&M Florestal Ltda. (clone 1 = híbrido de Eucalyptus urophylla $\mathrm{x}$ Eucalyptus grandis) e Celulose Nipo-Brasileira S.A. -CENIBRA (clones 2 e 3 = híbrido de Eucalyptus grandis $\mathrm{x}$ Eucalyptus urophylla). Esses clones foram inicialmente propagados vegetativamente por estaquia e introduzidos em laboratório de cultura de tecidos pela técnica de micropropagação via gemas axilares, os quais passaram por sucessivos subcultivos na fase de multiplicação, visando ao seu rejuvenescimento. Os clones 1,2 e 3 encontravam-se em banco clonal nos subcultivos $25^{\circ}, 19^{\circ}$ e $22^{\circ}$, respectivamente, quando foi iniciado o presente estudo.

O meio de cultura utilizado para multiplicação do material foi composto pelos sais básicos de MS (MURASHIGE e SKOOG, 1962), vitaminas de White (WHITE, 1943), acrescidos de mioinositol (100 $\mathrm{mg} \mathrm{L}^{-1}$ ), PVP (800 $\left.\mathrm{mg} \mathrm{L}^{-1}\right)$, sacarose (3\%), ágar granulado MERCK (0,5\%), 0,3 $\mathrm{mg} \mathrm{L}^{-1}$ de BAP e 0,01 $\mathrm{mg} \mathrm{L}^{-1}$ de ANA, com $\mathrm{pH}$ ajustado para 5,8. O trabalho foi desenvolvido no Laboratório de Cultura de Tecidos II do Instituto de Biotecnologia Aplicada à Agropecuária (BIOAGRO), da Universidade Federal de Viçosa, em Viçosa, MG.

\subsection{Metodologia}

O presente trabalho de propagação por organogênese in vitro foi composto de duas etapas, sendo 
a primeira referente à produção de gemas alongadas in vitro, para obtenção dos explantes caulinares, e a segunda, para obtenção dos calos e regeneração das gemas adventícias.

Para obtenção do explante caulinar, foi utilizada a técnica de micropropagação através da proliferação de gemas axilares, conforme descrito no item 2.1, modificando-se apenas a concentração dos reguladores de crescimento para $0,1 \mathrm{mg} \mathrm{L}^{-1}$ de ANA e 0,05 $\mathrm{mg} \mathrm{L}^{-1}$ de BAP, visando promover o alongamento das brotações em banco clonal.

A partir das brotações alongadas, os explantes caulinares foram obtidos dos segmentos internodais, tomando-se o cuidado para que esses segmentos internodais não contivessem gemas axilares (Figura 1).

No presente trabalho, a micropropagação por organogênese foi composta pelas fases de indução de calo e da regeneração das gemas, utilizando-se o meio de cultura MS acrescido de mioinositol (100 mg $\left.\mathrm{L}^{-1}\right)$, PVP (800 $\left.\mathrm{mg} \mathrm{L}^{-1}\right)$, sacarose (2\%), ágar granulado MERCK $(0,5 \%)$, com pH ajustado para 5,6. Para minimização das contaminações por bactérias, acrescentaram-se aos meios de cultura $300 \mathrm{mg} \mathrm{L}^{-1}$ do antibiótico Timentim, após autoclavagem.

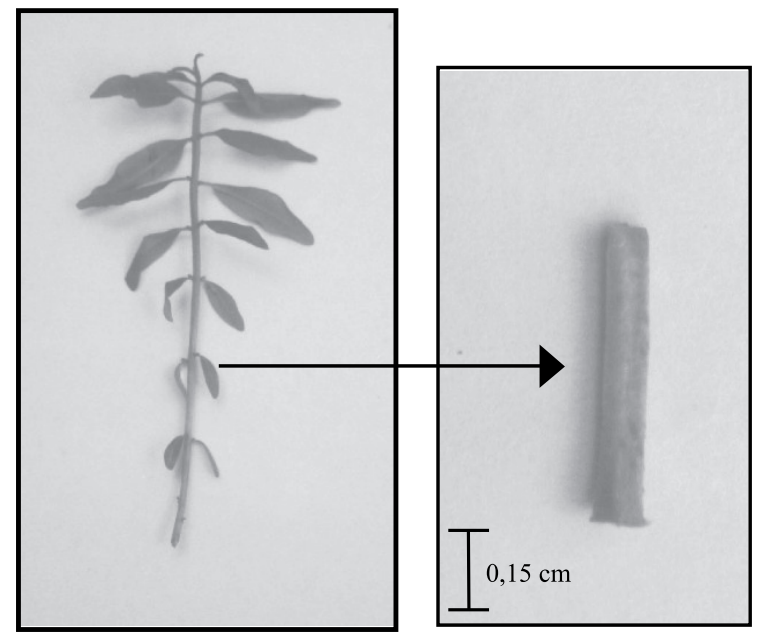

Figura 1-Explante caulinar de clones híbridos de Eucalyptus grandis $x$ Eucalyptus urophylla utilizados na organogênese in vitro.

Figure 1-Stem explants from hybrid clones of Eucalyptus grandis $x$ Eucalyptus urophylla used in the in vitro organogenesis.
Quanto a avaliação dos tipos e concentrações de reguladores de crescimento na organogênese dos três clones de eucalipto foram utilizadas, na fase de indução de calos, combinações de TDZ e ANA, respectivamente, em $\mathrm{mg} \mathrm{L}^{-1}$ (T1: 0,5 + 0,5; T2: 0,5 + 0,1; T3: 0,05 + 0,01; e T4: 1,0 + 0,1; e de BAP com ANA, respectivamente, em $\mathrm{mg} \mathrm{L}^{-1}$ ( T5: 0,1 + 0,1; T6: 0,5 + 0,5; T7: 1,0 + 3,0; e T8: 1,0 + 1,0). Na fase de regeneração de gemas, foram usadas combinações de BAP e ANA, respectivamente, em $\mathrm{mg} \mathrm{L}^{-1} \quad$ (T1: 0,2 + 0,2; T2: 0,3 + 0,0; T3: 0,5 + 0,2; T4: 1,0+0,0; T5: 1,0+3,0; T6: 3,0+0,0; е T7: $0,1+0,05)$.

\subsubsection{Condução e avaliações experimentais}

Os explantes caulinares foram colocados nos meios de indução de calos, em placas de Petri descartáveis estéreis $(60 \times 15 \mathrm{~mm})$. Cada placa continha $12 \mathrm{~mL}$ de meio de cultura e cinco explantes, constituindo-se, assim, uma unidade experimental. Cada tratamento foi constituído por 10 repetições, e o delineamento experimental utilizado foi o inteiramente casualizado.

$\mathrm{Na}$ fase de indução de calos, as placas foram mantidas em regime de escuridão, na temperatura de $27 \pm 2{ }^{\circ} \mathrm{C}$, pelo período de cinco semanas, sendo, ao final desse tempo, realizada uma avaliação quanto a intensidade de calejamento, aspecto geral do calo (textura e coloração) e oxidação do explante. O critério adotado na avaliação da intensidade de calejamento foi: $1=$ pouco calejamento, $2=$ calejamento médio e $3=$ calejamento intenso.

Quanto à textura, a qual diz respeito à coesão entre as células que formam o calo, no presente estudo ela foi avaliada em friável (células frouxamente ligadas), compacta (células firmemente ligadas) e texturas intermediárias entre estas, classificadas como semifriáveis e semicompactas. A textura semicompacta é caracterizada como aquela intermediária entre a compacta e a semifriável, e a semifriável é a intermediária entre a semicompacta e a friável.

Em relação às colorações avaliadas na fase de indução de calos, elas foram classificadas como branco, branco com bege, bege-claro e bege-escuro. $\mathrm{O}$ begeescuro refere-se a calos de coloração mais escura, mas que não estão oxidados.

Em observações quanto à região do calejamento, foi verificado se o calejamento ocorreu em todo o explante ou somente nas extremidades dele. Veri-

R. Árvore, Viçosa-MG, v.28, n.5, p.643-653, 2004 
ficou-se também a presença de oxidação.

Com base na avaliação realizada, na fase de indução de calo foi selecionado o melhor tratamento para cada clone, o qual foi repetido para obtenção de calos suficientes para a fase seguinte.

Na regeneração de gemas, novos calos foram obtidos através dos explantes caulinares de cada clone proveniente do melhor tratamento da fase anterior. Eles foram cultivados em novo meio de cultura (conforme descrito em 2.2) em placas de Petri descartáveis estéreis (60 x $15 \mathrm{~mm}$ ) contendo $12 \mathrm{~mL}$ de meio de cultura com cinco calos por placa, sendo 10 placas por tratamento de reguladores de crescimento (conforme descrito em 2.2), e mantidos na temperatura de $27 \pm 2{ }^{\circ} \mathrm{C}$, sob fotoperíodo de 16 horas de luz e oito horas de escuro e densidade luminosa de $36 \mu \mathrm{mol} \mathrm{m}^{-2} \mathrm{~s}^{-1}$, sendo utilizado lâmpada luz do dia branca fluorescente de 20 $\mathrm{W}$ por 35 dias.

A avaliação da capacidade organogênica do material para cada tratamento com calos provenientes de explantes caulinares foi tomada em porcentagem de calos apresentando gemas regeneradas e número de brotações por calo, como também mudanças ocorridas no aspecto desses calos após a transferência para a condição de luminosidade.

As gemas regeneradas foram transferidas para meio de alongamento composto pelos sais básicos MS e vitaminas White, acrescidos de mioinositol (100 mg $\left.\mathrm{L}^{-1}\right)$, PVP (800 $\left.\mathrm{mg} \mathrm{L}^{-1}\right)$, sacarose (3\%), ágar granulado MERCK (0,5\%), 0,05 $\mathrm{mg} \mathrm{L}^{-1}$ de BAP e 0,1 $\mathrm{mg} \mathrm{L}^{-1} \mathrm{de}$ ANA, com pH ajustado para 5,8.

Para o enraizamento das brotações foi utilizado o meio composto pelos sais básicos MS e vitaminas de White, acrescidos de mioinositol (100 $\mathrm{mg} \mathrm{L}^{-1}$ ), PVP (800 $\mathrm{mg} \mathrm{L}^{-1}$ ), sacarose (3\%), ágar granulado MERCK (0,5\%) e 1,0 $\mathrm{mg} \mathrm{L}^{-1}$ de AIB (ácido indolbutírico), com $\mathrm{pH}$ ajustado para 5,8 .

\subsubsection{Análise histológica}

Para confirmação de que as gemas regeneradas tratavam de gemas adventícias e não gemas pré-formadas, foi realizada a análise histológica de uma fração do material regenerado.

Para a condução da análise histológica foram selecionados, aleatoriamente, explantes caulinares que apresentaram regeneração, os quais foram submeti- dos aos procedimentos necessários à confecção dos cortes histológicos.

Amostras dos tecidos in vitro foram coletadas e fixadas em FAA $50 \%$, pelo período de 24 horas. As amostras foram lavadas em álcool etílico 70\%, desidratadas em série alcoólica (álcool butílico) e embebidas em parafina, segundo Johansen (1940). Seções de $10 \mathrm{~mm}$ de espessura foram coradas em combinação fuccina básica e azul-de-astra e montadas em bálsamodo-canadá.

\section{RESULTADOS E DISCUSSÃO}

\subsection{Intensidade de calejamento}

Observou-se que os clones responderam, de forma diferente, aos tratamentos com reguladores de crescimento, em que o clone 1 foi o que apresentou os melhores resultados de calejamento, seguido pelos clones 2 e 3 (Figura 2). A classe de intensidade de calejamento 3 foi verificada no clone 1 , em quatro dos oito tratamentos; e no clone 2, em um dos oito tratamentos, todos utilizando TDZ.

Nos três clones, os melhores resultados ocorreram nos tratamentos com os reguladores de crescimento TDZ e ANA, sendo o tratamento $T_{2}$ para o clone 1 e $\mathrm{T}_{3}$ para os clones 2 e 3. Segundo Murthy et al. (1998), o TDZ apresenta uma melhor "performance" na obtenção de calos em relação a outras citocininas. Esse melhor desempenho do TDZ, aparentemente, pode estar relacionado a uma maior atividade citocinínica ou a uma forma de ação diferente de outras citocininas durante os processos de desdiferenciação e rediferenciação celular (KANEDA et al., 1997), como também ao acúmulo de auxinas e citocininas endógenas nos tecidos pela ação do TDZ (MURTHY et al., 1995).

No clone 1, os tratamentos utilizando TDZ foram superiores aos com BAP, visto apresentar as maiores porcentagens de calejamento nas classes de intensidade 2 e 3 . O calejamento em todo o explante ocorreu em $100 \%$ dos calos formados nos tratamentos $\mathrm{T}_{1}, \mathrm{~T}_{2}$ $\mathrm{e}_{4}$ e em $98 \%$ dos calos formados em $\mathrm{T}_{3}$ (Figura 3A). Nos tratamentos utilizando BAP, embora o calejamento se desse na maioria dos casos em todo o explante, o calejamento somente nas extremidades foi observado em maiores proporções em $\mathrm{T}_{5}$, com $44 \%$, e em menores proporções em $\mathrm{T}_{7}$, com 16\% (Figura 3-B). 


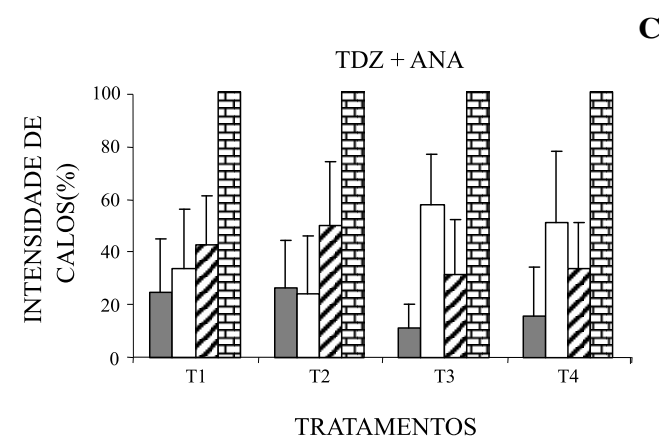

CLONE 1
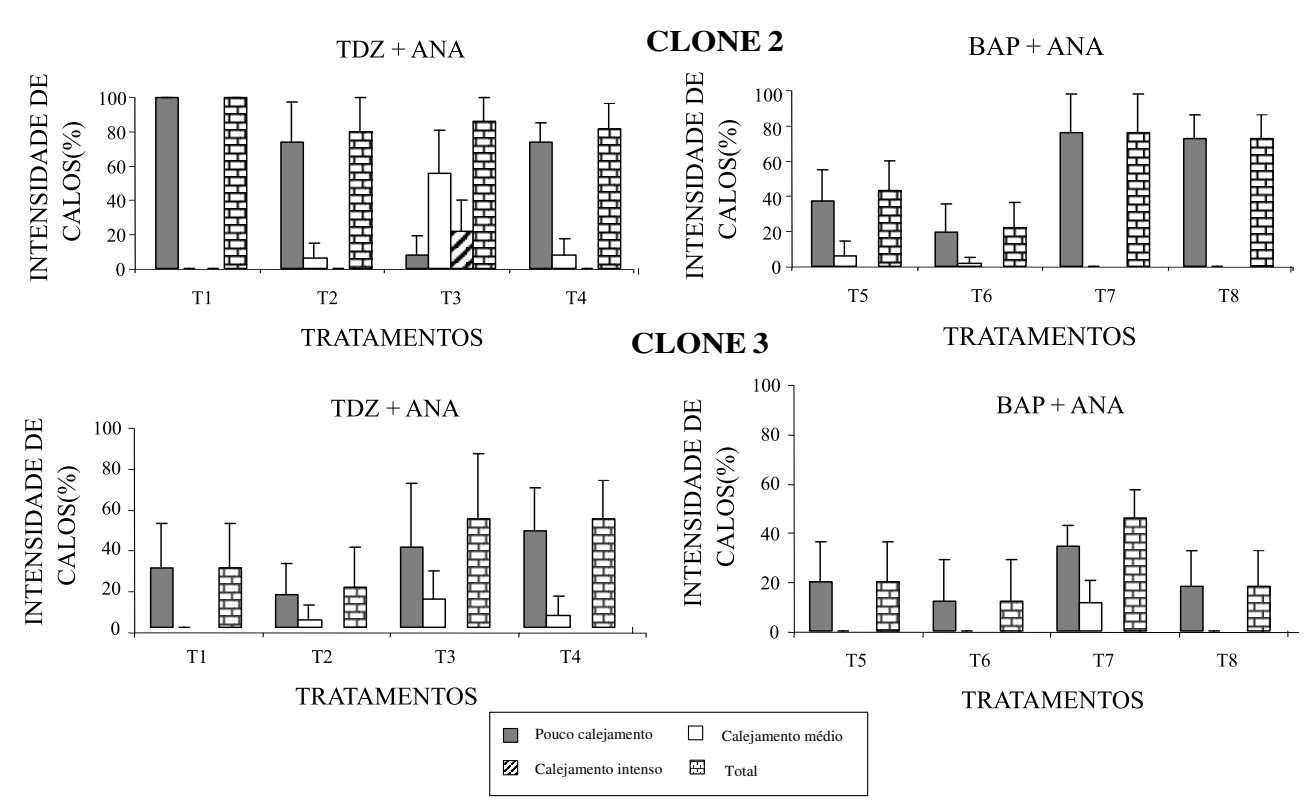

Figura 2 - Intensidade de calogênese a partir de explante caulinar, em função dos tratamentos com reguladores de crescimento (TDZ, BAP e ANA), avaliada em três clones de Eucalyptus grandis x Eucalyptus urophylla. Barras verticais indicam os desvios das médias.

Figure 2 - Intensity of callus forming in stem explants, by growth regulators treatments (TDZ, BAP and ANA) evaluated in three clones of Eucalyptus grandis x Eucalyptus urophylla. Vertical bars indicate the deviations of the averages.
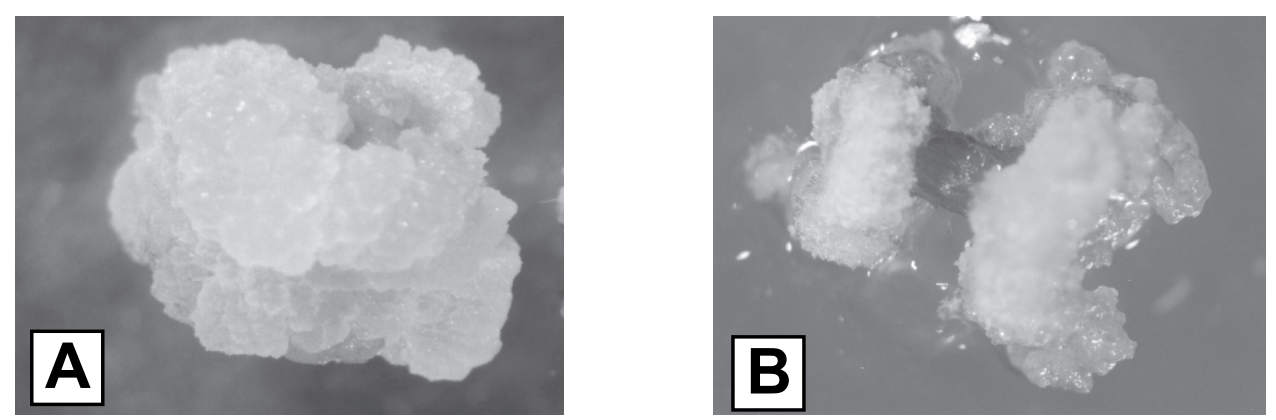

Figura 3 - Explante caulinar com calejamento em toda a superfície (A) e apenas nas extremidades (B) do clone 1, após 35 dias de cultivo na ausência de luz.

Figure 3 - Stem explants showing callus forming in the whole surface $(A)$ and just in the extremities $(B)$ of the clone 1 , after 35 days under darkness regime. 
Quanto ao clone 2, os tratamentos utilizando TDZ e ANA também foram superiores aos com BAP e ANA. Os tratamentos com TDZ proporcionaram calejamento em todo o explante em $100 \%$ dos calos formados nos tratamentos $\mathrm{T}_{1}, \mathrm{~T}_{2}$ e $\mathrm{T}_{4}$ e em $98 \%$ dos formados em $\mathrm{T}_{3}$. Nos tratamentos com BAP, o calejamento somente nas extremidades foi observado em maiores proporções em $\mathrm{T}_{5}$, com $68 \%$. A oxidação foi verificada nos calos na maioria dos tratamentos, com exceção do $T_{1}$, com maiores intensidades nos tratamentos utilizando BAP. A tendência de maior oxidação de explantes de Fagus sylvatica em meios de cultura usando BAP, em comparação com os utilizando TDZ, também foi notada por Vieitez e San-José (1996).

Os resultados obtidos nos tratamentos com TDZ e ANA com o clone 3 se mostraram ligeiramente superiores aos de BAP e ANA, não sendo observada diferença acentuada entre os tratamentos com as duas citocininas, como ocorreu com os clones 1 e 2 . Nos tratamentos com TDZ, foi verificado o calejamento ao longo do explante em $100 \%$ daqueles que calejaram, enquanto nos tratamentos com BAP o calejamento ocorreu somente nas extremidades também em $100 \%$ dos explantes que calejaram nos tratamentos $\mathrm{T}_{5}$ e $\mathrm{T}_{6}$ e, em menores proporções, nos tratamentos $\mathrm{T}_{7}(6 \%)$ e $\mathrm{T}_{8}(22 \%)$. A oxidação ocorreu nos explantes em todos os tratamentos, com maiores intensidades nos tratamentos com BAP.

As vantagens da utilização conjunta dos reguladores de crescimento TDZ e ANA foram citadas por Lu (1993) e Hosokawa et al. (1996), em que o TDZ apresentou maior eficiência na presença de ANA. Contudo, longas exposições ao TDZ podem causar hiper-hidricidade, crescimento anormal de gemas e dificuldade no enraizamento (LU, 1993).

De forma geral, com base nesses resultados, o clone 1 apresentou os melhores resultados com a combinação de $0,5 \mathrm{mg} \mathrm{L}^{-1}$ de TDZe $0,1 \mathrm{mg} \mathrm{L}^{-1} \operatorname{deANA}\left(\mathrm{T}_{2}\right)$.

\subsection{Textura dos calos}

Em relação ao clone 1, os tratamentos com BAP e ANA proporcionaram a maioria dos calos compactos $\left(\mathrm{T}_{5}\right.$ e $\left.\mathrm{T}_{6}\right)$ e semicompactos $\left(\mathrm{T}_{7}\right.$ e $\left.\mathrm{T}_{8}\right)$, enquanto os tratamentos com TDZ e ANA resultaram em calos semifriáveis, em sua maioria. Foi observada nos tratamentos $\mathrm{T}_{5}, \mathrm{~T}_{7}$ e $\mathrm{T}_{8}$ com BAP uma correlação entre os calos compactos formados e a presença de estruturas compactas nodulares formadas na superfície destes, principalmente nas extremidades do explante. Quanto à coloração, houve predominância do bege-claro em todos os tratamentos (Figura 4).

Quanto ao clone 2, verificou-se a formação de calos compactos e semicompactos, em que os tratamentos com BAP e ANA, com exceção do $\mathrm{T}_{5}$, apresentaram a maior parte dos calos semicompactos. Os tratamentos com TDZ e ANA, à exceção do $\mathrm{T}_{3}$, exibiram a maior parte dos calos compactos. Houve a predominância das colorações branca mesclada com bege e bege-claro nos tratamentos com TDZ e branca mesclada com bege nos tratamentos com BAP.

No clone 3 foram formados calos compactos e semicompactos, em que os tratamentos com TDZ e ANA, à exceção do $\mathrm{T}_{4}$, proporcionaram calos mais compactos. Nos tratamentos com BAP e ANA, as maiores concentrações de BAP nos tratamentos $T_{7}$ e $T_{8}$ proporcionaram calos mais semicompactos. Constatou-se nos tratamentos $\mathrm{T}_{5}, \mathrm{~T}_{6} \mathrm{e} \mathrm{T}_{8}$ uma correlação entre os calos compactos formados e a presença de estruturas compactas nodulares formadas na superfície desses calos, principalmente nas extremidades do explante.

Nos tratamentos com TDZ houve a predominância das colorações branca mesclada com bege e begeclaro, e nos tratamentos com BAP predominou a coloração bege-escura. Pôde ser observado que a concentração e o tipo de reguladores de crescimento utilizados influenciaram a coloração e textura dos calos nos três clones de Eucalyptus grandis $x$ E. urophylla em estudo, concordando com os resultados obtidos por Warrag et al. (1991) e Hervé et al. (2001).

A partir dos resultados da fase de indução de calos para explante caulinar, o melhor tratamento foi selecionado, principalmente, pela capacidade do explante em responder, em termos de intensidade de calogênese, a determinado tratamento hormonal. Assim, foram selecionados, para serem repetidos e utilizados na fase de regeneração de gemas, os tratamentos $T_{2}$ (0,5 $\mathrm{mg} \mathrm{L}^{-1}$ de TDZ e $0,1 \mathrm{mg} \mathrm{L}^{-1}$ de ANA) para o clone 1 e $_{3}\left(0,05 \mathrm{mg} \mathrm{L}^{-1}\right.$ de TDZ + 0,01 $\mathrm{mg} \mathrm{L}^{-1}$ de ANA) para os clones 2 e 3 .

\subsection{Regeneração de gemas}

Somente os clones 1 e 3 apresentaram alguma resposta de regeneração de gemas nos tratamentos com reguladores de crescimento (Figuras 5 e 6). No clone 1 , foi obtido resposta em somente $1 \%$ dos calos 
no tratamento $\mathrm{T}_{1}$, enquanto no clone 3 o melhor resultado foi conseguido no tratamento $\mathrm{T}_{4}$, com $5 \%$ dos calos formados a partir de explantes caulinares regenerando gemas.

Foram observadas, nos três clones, mudanças quanto a coloração e textura dos calos, após estes serem transferidos para o meio de regeneração e cultivados à luz. Os calos passaram a apresentar maior compactação e, de forma geral, coloração verde, cuja tonalidade variou de acordo com o clone.

Dos três clones em estudo, o clone 1 foi o que apresentou calos verdes com maior intensidade. Em alguns casos, foi observada a formação de estrutu- ras nodulares compactas na superfície do calo, em que as gemas formadas no explante caulinar no tratamento $\mathrm{T}_{1}$ se desenvolveram a partir de regiões nodulares desse calo.

Em relação ao clone 2, em todos os tratamentos com reguladores de crescimento na fase de regeneração de gemas foi observado crescente aumento no escurecimento do meio de cultura com o tempo, provavelmente pela liberação de compostos fenólicos. Dos calos que não se oxidaram durante o período até a avaliação, pequena parcela apresentou coloração esbranquiçada, sendo a maioria de coloração esverdeada. Parte dos calos não oxidados desenvolveu estruturas nodulares compactas em sua superfície.

\section{CLONE 1}
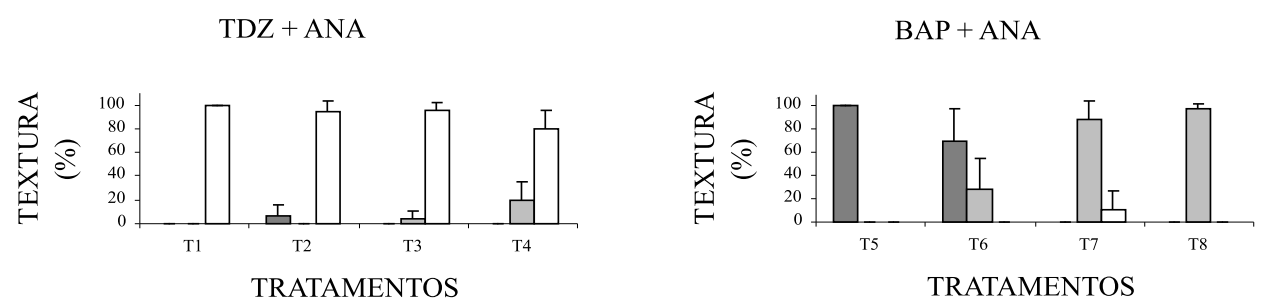

CLONE 2
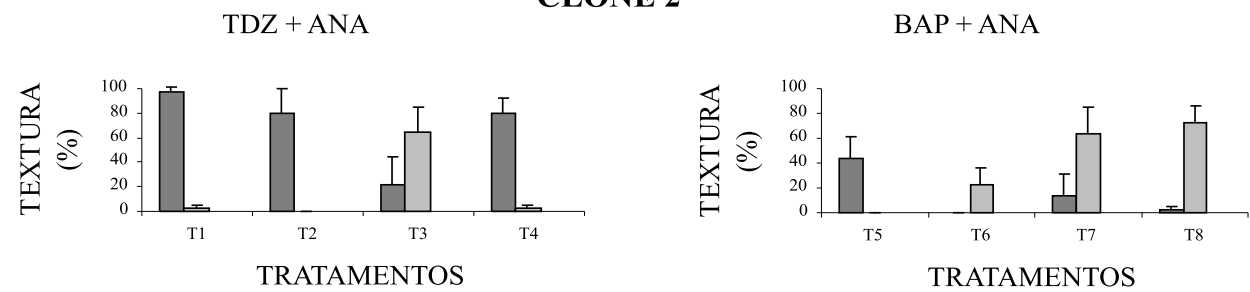

\section{CLONE 3}

$\mathrm{TDZ}+\mathrm{ANA}$

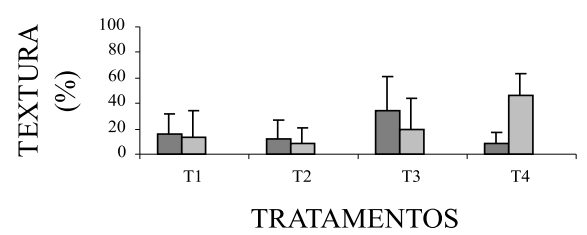

$\mathrm{BAP}+\mathrm{ANA}$

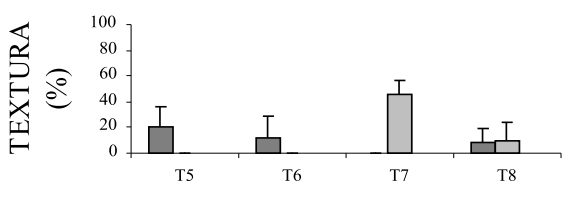

TRATAMENTOS

$\square$ Compacto $\square$ Semicompacto $\square$ Semifriável

Figura 4 - Textura observada em calos obtidos a partir de explante caulinar, em função dos tratamentos com reguladores de crescimento (TDZ, BAP e ANA), avaliada em três clones de Eucalyptus grandis x Eucalyptus urophylla. Barras verticais indicam os desvios das médias.

Figure 4 - Texture observed in callus obtained of stem explants, due to the growth regulator treatments (TDZ, BAP and ANA). evaluated in three clones of Eucalyptus grandis $x$ Eucalyptus urophylla. Vertical bars indicate the deviations of the averages. 

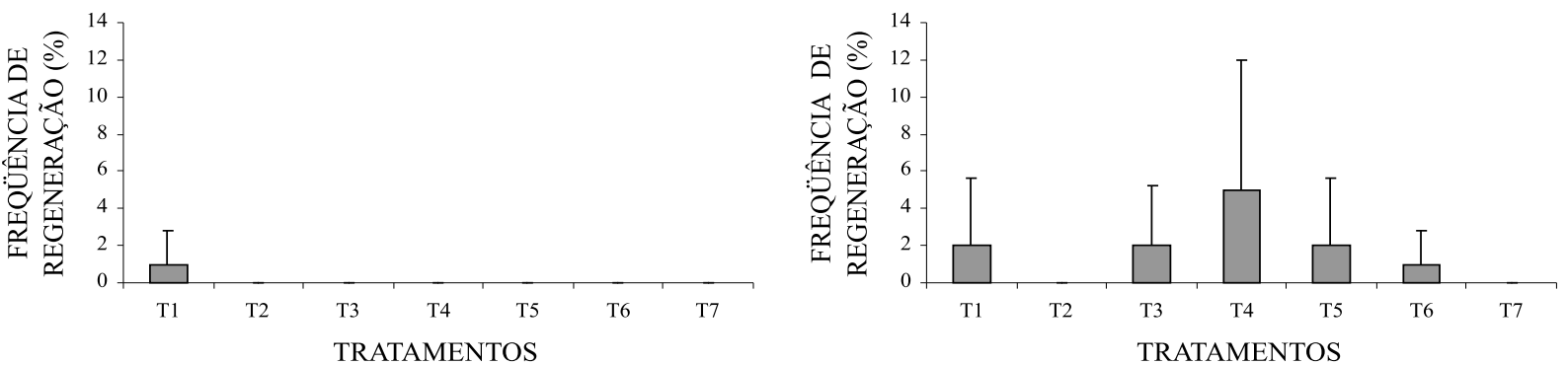

Figura 5 - Percentual de calos com regeneração de gemas a partir de calos formados de explante caulinar, em função dos tratamentos com reguladores de crescimento (BAP e ANA), avaliado nos clones 1 e 3. Barras verticais indicam os desvios das médias.

Figure 5 - Percentile of callus with regeneration of buds coming of formed callus of stem explants, due to the growth regulator treatments (BAP and ANA) evaluated in clones 1 and 3. Vertical bars indicate the deviations of the averages.

CLONE 1

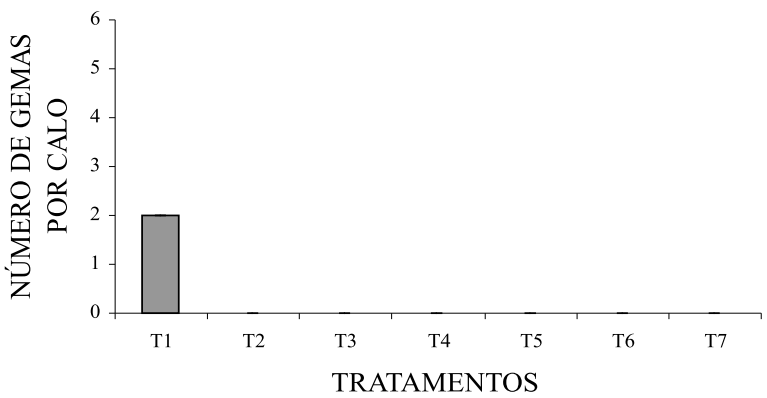

CLONE 3

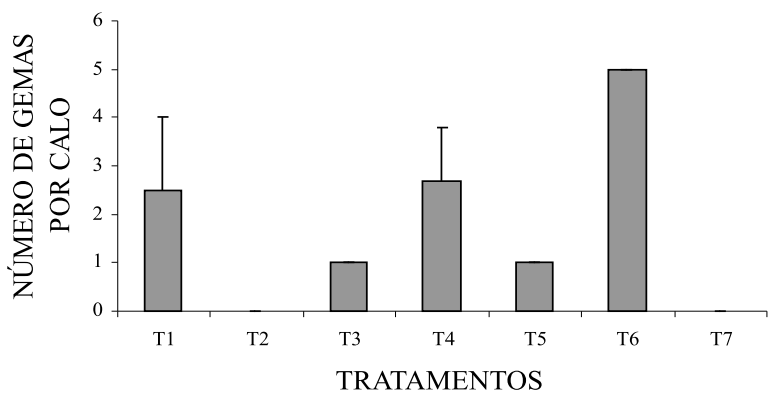

Figura 6 - Número médio de gemas por calo regenerado em explante caulinar, em função dos tratamentos com reguladores de crescimento (BAP e ANA), avaliado nos clones 1 e 3 . Barras verticais indicam os desvios das médias.

Figure 6 -Medium number of buds for regenerate callus by stem explants, due to the growth regulator treatments (BAP and ANA) evaluated in clones 1 and 3. Vertical bars indicate the deviations of the averages.

O clone 3, embora tenha sido o que melhor respondeu à organogênese em explante caulinar, teve porcentual alto de calos oxidados ou em fase de oxidação quando foi realizada a avaliação $\left(75 \%\right.$ em $\mathrm{T}_{1}$, $80 \%$ em $\mathrm{T}_{2}, 81 \% \mathrm{em} \mathrm{T}_{3}, 67 \% \mathrm{em} \mathrm{T}_{4}, 83 \%$ em $\mathrm{T}_{5}, 83 \%$ em $\mathrm{T}_{6}$ e $80 \% \mathrm{em} \mathrm{T}_{7}$ ). As gemas produzidas, pouco desenvolvidas, formaram-se a partir de pequenas partes de tecidos nodulares compactos nos calos e apresentavam aspecto hiper-hídrico, estando em alguns casos associadas à antocianina (Figura 7). A relação entre a textura compacta e a capacidade de regeneração de gemas foi também observada por Hervé et al. (2001), que verificaram que calos formados a partir de segmentos internodais de clones de Eucalyptus gunnii apresentavam, nas extremidades dos explantes, o desenvolvimento de protuberâncias densas que culminavam na regeneração de gemas.

R. Árvore, Viçosa-MG, v.28, n.5, p.643-653, 2004
De acordo com os resultados, embora a taxa de oxidação no clone 3 tenha se mostrado alta, este apresentou a melhor "performance" na avaliação da capacidade organogênica a partir de calos formados em explantes caulinares quando cultivados em meio de regeneração com 1,0 $\mathrm{mg} \mathrm{L}^{-1}$ de BAP. Vale salientar que os resultados obtidos em relação ao porcentual de regeneração foram inferiores aos de Subbaiah e Minocha (1990), Tibok et al. (1995), Azmi et al. (1997), Bandyopadhyay et al. (1999) e Lainé e David (1994), sendo próximos dos resultados alcançados por Hervé et al. (2001), que, utilizando segmentos internodais de clones de Eucalyptus gunnii, obtiveram 9,9\% de calos regenerando gemas com o número médio destas formadas por calo igual a 3,4 .

Os regenerantes obtidos foram transferidos para 
meio de alongamento, em que as gemas formadas, por serem pouco desenvolvidas e apresentarem hiperhidricidade, não exibiram resposta no meio de alongamento.

Deve-se ressaltar que, na confecção dos explantes caulinares, principalmente quando estes não são realizados com o auxílio de lupa, existe a possibilidade de gemas axilares presentes ao longo das brotações permanecerem nos segmentos internodais utilizados como explantes, vindo, com isso, a mascarar os resultados.

\subsection{Análise histológica}

As análises histológicas realizadas no explante caulinar revelaram a origem adventícia das gemas formadas. Em corte transversal, houve intensa desdife- renciação de células a partir de células parenquimáticas associadas ou não à região vascular, resultando em considerável expansão radial dos explantes (Figura 8A). De maneira semelhante, as células da periferia dos explantes apresentaram significativa divisão celular no plano predominantemente periclinal, contribuindo também para a expansão radial. Todavia, em algumas regiões dos explantes houve tendência de ocorrer a rediferenciação dessas células e a conseguinte formação de gemas (Figura 8B).

A realização de análises histológicas em trabalhos com organogênese in vitro é fundamental para a confirmação da origem das gemas formadas em cultivo, excluindo-se a possibilidade de interpretação equivocada dos resultados advindos da presença de gemas pré-formadas no explante original.
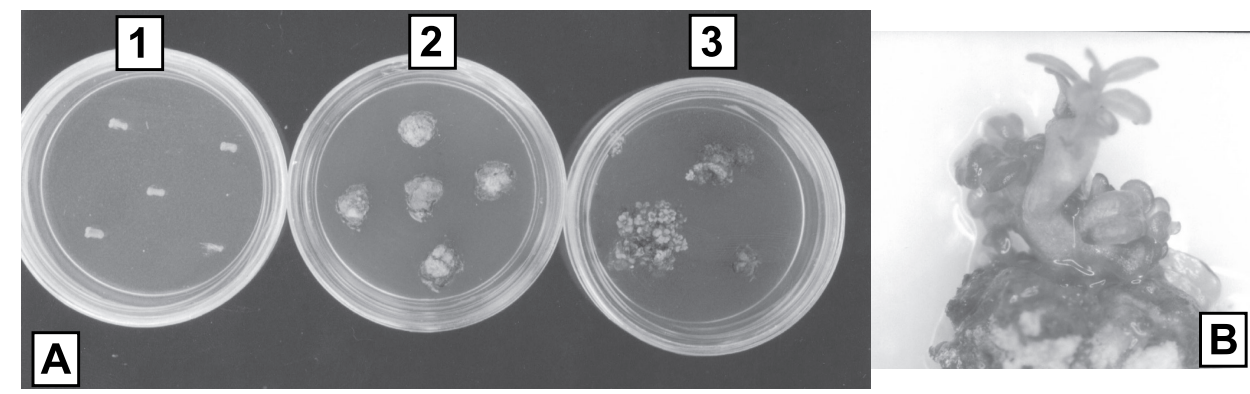

Figura 7 - (A) Organogênese em explante caulinar nas fases inicial (1), de calejamento obtido após 35 dias no escuro (2) e de regeneração de gemas adventícias do clone 3 obtida 35 dias após sua transferência para luz (3). (B) Detalhe das gemas adventícias desenvolvidas em explante caulinar do clone 3.

Figure 7 - (A) Organogenesis in stem explants in the initial phases (1), callus forming after 35 days under darkness regime (2) and the regeneration of adventitious buds of clone 3 obtained 35 days after its transfer to light (3). (B) Detail of the adventitious buds forming by stem explants of clone 3.
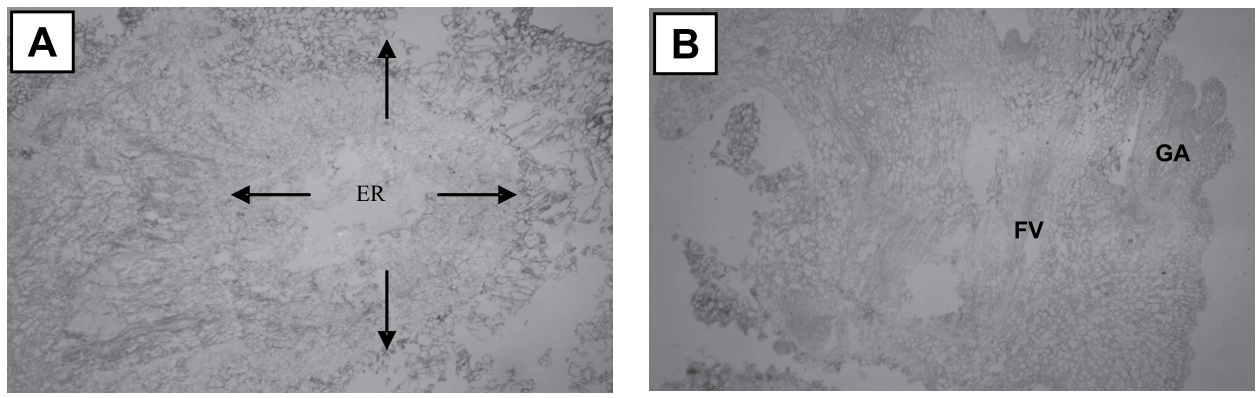

Figura 8 - Fotomicrografias de cortes transversal (A) e longitudinal (B) de expante caulinar. A-Corte transversal evidenciando a proliferação celular e a conseguinte expansão radial (ER) do explante caulinar. B - Formação de gemas adventícias (GA) apresentando conexão dos feixes vasculares (FV) com o tecido original do explante.

Figure 8 - photomicrographs of traverse (A) and longitudinal section (B) by stem explants. A - transversal section evidencing the cell proliferation and the rising radial expansion $(E R)$ of the stem explants. $B$ - adventitious buds formation $G A)$ showing connection of the vascular system $(F V)$ with the original tissue of the explants. 


\section{CONCLUSÕES}

Pode-se concluir, com relação aos clones de Eucalyptus grandis $x$ Eucalyptus uorphylla avaliados, que os reguladores de crescimento TDZ e ANA proporcionam maiores índices de calejamento, e a sua concentração varia de acordo com o clone utilizado. A intensidade de calejamento e a textura do calo são os parâmetros que devem ser usados na escolha de um tratamento objetivando a organogênese em eucalipto.

\section{REFERÊNCIAS BIBLIOGRÁFICAS}

AZMI, A. et al. High frequency plant regeneration from Eucalyptus globulus Labill. hypocotyls: ontogenesis and ploidy level of the regenerants.

Plant Cell, Tissue and Organ Culture, v.51, p.9-16, 1997.

BANDYOPADHYAY, S. et al. Efficient plant regeneration from seedling of two commercially important temperate eucalypt species- Eucalyptus nitens and E. globulus. Plant Science, v.140, p.189-198, 1999.

BONGA, J. M.; von ADERKAS, P. In vitro culture of trees. Netherlands: Kluwer Academic Publishers, 1992. 236 p.

CHEN, Z. Z.; TSAY, J. Y.; CHUNG, J. D. Callus culture of Eucalyptus grandis $\mathrm{x}$ urophylla and preliminary studies on organogênesis and Agrobacterium-mediated transformation. Taiwan Journal Forestry Science, v.11, n.1, p.43$52,1996$.

COENEN, C.; LOMAX, T. L. Auxin-cytokinin interactions in higher plants: old problems and new tools. Trends in Plant Science, v.2, n.9, p.351-356, 1997.

FERREIRA, M. E.; CALDAS, L. S.; PEREIRA, E. A. Aplicações da cultura de tecidos no melhoramento genético de plantas. In: TORRES, A. C.; CALDAS, L. S.; BUSO, J. A. (Eds.). Cultura de tecidos e transformação genética de plantas. Brasília: EMBRAPA-SPI/ EMBRAPA-CNPH, 1998. v.1.p.21-43.

HERVÉ, P. et al. A procedure for shoot organogenesis in vitro from leaves and nodes of an elite Eucalyptus gunnii clone: comparative histology. Plant Science, v.161, p.645-653, 2001.
HO, C. K. et al. Agrobacterium tumefaciensmediated transformation of Eucalyptus camaldulensis and production of transgenic plants. Plant Cell Reports, v.17, p.675-680, 1998.

HOSOKAWA, K. et al. Adventitious shoot regeneration from leaf, stem and root explants of commercial cultivars of Gentiana. Plant Cell Reports, v.15, p.578-581, 1996.

JOHANSEN, D. A. Plant microtechnique. New York: McGraw-Hill, 1940. 523 p.

KANEDA, Y. et al. Combination of thidiazuron and basal media with low salt concentrations increases the frequency of shoot organogenesis in soybeans [Glycine max (L.) Merr.]. Plant Cell Reports, v.17, p.8-12, 1997.

LAINÉ, E.; DAVID, A. Regeneration of plants from leaf explants of micropropagated clonal Eucalyptus grandis. Plant Cell Reports, v.13, p.473-476, 1994.

LU, C. Y.; The use of thidiazuron in tissue culture. In Vitro Cellular and Development Biology- Plant, v.29, p.92-96, 1993.

MULLINS, K. V. et al. Regeneration and transformation of Eucalyptus camaldulensis. Plant Cell Reports, v.16, n.11, p.787-791, 1997.

MURASHIGE, T.; SKOOG, F. A revised medium for rapid growth with tobacco tissue cultures.

Physiologia Plantarum, v.15, p.473-497, 1962.

MURTHY, B. N. S.; MURCH, S. J.; SAXENA, P. K. Thidiazuron- induced somatic embryogenesis in intact seedlings of peanut (Arachis hypogaea): endogenous growth regulator levels and significance of cotyledons. Physiologia Plantarum, v.94, p.268-276, 1995.

MURTHY, B. N. S.; MURCH, S. J.; SAXENA, P. K. Thidiazuron: a potent regulator of in vitro plant morphogenesis. In Vitro Cellular and Development Biology- Plant, v.34, p.267$275,1998$. 
PIERIK, R. L. M. In vitro culture of higher plants. 4.ed. Netherlands: Kluwer Academic Publishers, 1997. 348 p.

SERRANO, L. et al. Genetic transformation of Eucalyptus globulus through biolistics:

complementary development of procedures for organogenesis from zygotic embryos and stable transformation of corresponding proliferating tissue. Journal of Experimental Botany, v.47, n.295, p.285-290, 1996.

SUBBAIAH, M. M.; MINOCHA, S. C. Shoot regeneration from stem and leaf callus of Eucalyptus tereticornis. Plant Cell Reports, v.9, p.370-373, 1990.

TIBOK, A. et al. Optimized plant regeneration from callus derived from seedling hypocotyls of Eucalyptus urophylla. Plant Science, v.110, p.139-145, 1995.
VIEITEZ, A. M.; SAN-JOSÉ, M. C. Adventitious shoot regeneration from Fagus sylvatica leaf explants in vitro. In Vitro Cellular Development and Biology- Plant, v.32, p.140-147, 1996.

WARRAG, E.; LESNEY, M. S.; ROCKWOOD, D. J. Nodule culture and regeneration of Eucalyptus grandis hybrids. Plant Cell Reports, v.9, p.586-589, 1991.

WHITE, P. R. Further evidence on the significance of glycine, pyridoxine and nicotinic acid in the nutrition of excised tomato roots. American Journal of Botany, v.30, p.33-36, 1943.

XAVIER, A.; COMÉRIO, J. Microestaquia: uma maximização da micropropagação de Eucalyptus. Revista Árvore, v.20, n.1, p.9-16,1996. 